\title{
Orthostatic stress testing in myalgic encephalomyelitis/chronic fatigue syndrome (ME/CFS) patients with or without concomitant fibromyalgia: effects on pressure pain thresholds and temporal summation
}

\author{
C (Linda) van Campen ${ }^{1}$, Peter Rowe ${ }^{2}$, Freek Verheugt ${ }^{3}$, and Frans Visser ${ }^{1}$ \\ ${ }^{1}$ Stichting Cardiozorg \\ ${ }^{2}$ Johns Hopkins University \\ ${ }^{3} \mathrm{OLVG}$
}

April 28, 2020

\begin{abstract}
Introduction: muscle pain/fibromyalgia (FM) is common among individuals with myalgic encephalomyelitis/chronic fatigue syndrome (ME/CFS). We recently demonstrated that during orthostatic stress testing, adults with ME/CFS reported increased pain. In the current study, we hypothesized that pain pressure thresholds (PPT) would decrease and temporal summation (windup) would increase after head-up tilt testing (HUT), and that the presence of co-morbid FM would be associated with greater change in both measures. Methods and Results: 248 ME/CFS patients (164 with FM and84 without FM), and 22 healthy controls $(\mathrm{HC})$ were analyzed. In $\mathrm{HC}$ there were no significant differences in PPT between pre- and post-HUT (finger: from 4.7(1.6) to 4.4(1.5); shoulder: from 2.8(1.0) to 2.9(1.0)). In ME/CFS patients with and without FM, a significant decrease in PPT post-HUT was found compared to HC (both $\mathrm{p}<0.0001$ ). Patients with FM had a lower PPT pre- and post-HUT (finger: from 2.0(0.9) to 1.5(0.8); shoulder: from 1.2(0.5) to 1.0(0.5) compared to patients without FM (finger: from 5.0(1.6) to 3.3(1.5); shoulder: from 2.2(0.9) to1.9(1.0) (p ranging from 0.001 to <0.0001). In contrast to $\mathrm{HC}$ in $\mathrm{ME} / \mathrm{CFS}$ patients windup was increased compared to HC pre-HUT (both $\mathrm{p}<0.0001$ ), but did not significantly change post-HUT. Conclusions: Pressure pain threshold decreased in ME/CFS patients with or without fibromyalgia after head-up tilt test (HUT), compared to healthy controls. Windup pre-and post-HUT was significantly higher compared to healthy controls, but did not change from pre- to post-HUT. These results demonstrate that, like exercise, orthostatic stress can negatively influence the physiology of pain perception in $\mathrm{ME} / \mathrm{CFS}$.
\end{abstract}

Orthostatic stress testing in myalgic encephalomyelitis/chronic fatigue syndrome (ME/CFS) patients with or without concomitant fibromyalgia: effects on pressure pain thresholds and temporal summation

C. (Linda) M.C. van Campen, $\mathrm{MD}^{1}$

Peter C. Rowe, $\mathrm{MD}^{2}$

Freek W.A. Verheugt, $\mathrm{MD}, \mathrm{PhD}^{3}$

Frans C. Visser, $\mathrm{MD}, \mathrm{PhD}^{1}$

1 Stichting CardioZorg, Planetenweg 5, 2132 HN Hoofddorp, Netherlands

2 Department of Paediatrics, Johns Hopkins University School of Medicine, Baltimore, MD, USA 
3 Onze Lieve Vrouwe Gasthuis (OLVG), Oosterpark 9, 1091 AC, Amsterdam, Netherlands

Address for correspondence:

C. (Linda) M.C. van Campen,

Planetenweg 5,

2132 HN Hoofddorp

Netherlands

Tel: +31206597888

Fax: +31205241235

Email address: info@stichtingcardiozorg.nl

Abstract

Introduction: muscle pain/fibromyalgia (FM) is common among individuals with myalgic encephalomyelitis/chronic fatigue syndrome (ME/CFS). We recently demonstrated that during orthostatic stress testing, adults with ME/CFS reported increased pain. In the current study, we hypothesized that pain pressure thresholds (PPT) would decrease and temporal summation (windup) would increase after head-up tilt testing (HUT), and that the presence of co-morbid FM would be associated with greater change in both measures.

Methods: We studied adult ME/CFS patients undergoing HUT. PPT and temporal summation (or windup) measurements were obtained pre- and post-HUT at the finger and shoulder.

Results: $248 \mathrm{ME} / \mathrm{CFS}$ patients (164 with FM and 84 without FM), and 22 healthy controls (HC) were analyzed. In HC there were no significant differences in PPT between pre- and post-HUT (finger: from 4.7(1.6) to 4.4(1.5); shoulder: from 2.8(1.0) to 2.9(1.0)). In ME/CFS patients with and without FM, a significant decrease in PPT post-HUT was found compared to HC (both $\mathrm{p}<0.0001$ ). Patients with FM had a lower PPT pre- and post-HUT (finger: from 2.0(0.9) to 1.5(0.8); shoulder: from 1.2(0.5) to 1.0(0.5) compared to patients without FM (finger: from 5.0(1.6) to 3.3(1.5); shoulder: from 2.2(0.9) to1.9(1.0) (p ranging from 0.001 to $<0.0001)$. Windup in $\mathrm{HC}$ did not significantly change from pre- to post-HUT. In ME/CFS patients with and without FM windup was increased compared to HC pre-HUT (both $\mathrm{p}<0.0001$ ), but did not significantly change post-HUT.

Conclusions: Pressure pain threshold decreased in ME/CFS patients with or without fibromyalgia after head-up tilt test (HUT), but did not change post-HUT in healthy controls. Windup pre-and post-HUT was significantly higher compared to healthy controls, but did not change from pre- to post-HUT. These results demonstrate that, like exercise, orthostatic stress can negatively influence the physiology of pain perception in ME/CFS.

Keywords : pressure pain threshold, temporal summation, windup, fibromyalgia, orthostatic intolerance, tilt table test, myalgic encephalomyelitis, chronic fatigue syndrome.

\section{Introduction}

Apart from the characteristic fatigue, patients with myalgic encephalomyelitis/chronic fatigue syndrome (ME/CFS) often experience chronic widespread and persistent pain(1-3). A population-based study revealed that $94 \%$ of the persons diagnosed with ME/CFS report muscle pain, and $84 \%$ report joint pain(4). In fact, there is a great overlap between ME/CFS and fibromyalgia (FM), a disease particularly characterized by musculoskeletal pain(1).

As has been demonstrated in those with $\operatorname{FM}(2,3)$, previous studies define central sensitization as the underlying mechanism maintaining chronic pain in ME/CFS patients(5-7). Central sensitization comprises 
hyper-excitement of the central neurons, altered sensory processing in the brain and malfunctioning descending pain inhibitory mechanisms(8). Furthermore, exercise-induced pain inhibition is not activated in patients with ME/CFS, resulting in lower pain thresholds and pain exacerbation after exercise(9-11).

There are several methods for estimating the intensity of a stimulus required to evoke a painful sensation in the skin: mechanical, chemical, electrical, and thermal(12). Algometry is a widely used technique for determining the effect of mechanical stimulation. It generates data on pressure pain thresholds (PPT)(13), or the degree of pressure required before the individual experiences pain. Lower thresholds indicate that pain is experienced with less pressure. Algometry is valid and reproducible, with high levels of interrater reliability(14-17). PPT is one of the most frequently methods used in FM to objectively assess severity(1823).

In ME/CFS patients studies have shown that pain is increased following exercise stress testing $(24,25)$. Furthermore, studies have shown that submaximal physical stress reduced pain thresholds both in FM and non-FM ME/CFS patients, whereas in healthy controls pain thresholds increased(11, 26, 27).

Another aspect of pain perception that can be studied using algometry is temporal summation (windup), which refers to an increased pain perception in response to repetitive painful stimuli. A meta-analysis in FM patients showed a significant increase in windup compared to $\mathrm{HC}(28)$.

In a previous study in ME/CFS patients, we demonstrated that orthostatic stress results in a cerebral blood flow reduction, and that the blood flow reduction is associated with onset or worsening of pain(CNP2019). In the current study, we hypothesized that PPT would be reduced and windup would increase after orthostatic stress testing in ME/CFS patients. For this purpose PPT and windup were measured before and after a head-up tilt test (HUT) in ME/CFS patients and in healthy controls (HC). We also hypothesized that among ME/CFS participants, the presence of co-morbid FM would lead to lower PPT and increased windup compared to those without FM.

\section{Materials and Methods}

Eligible participants :

Female individuals diagnosed with ME/CFS, who underwent HUT at Stichting CardioZorg between November 2014 and April 2018 because of a clinical suspicion of orthostatic intolerance (OI), and in whom a complete set of the PPT's pre- and post-HUT was available, were included in this study. Male patients were not studied because of differences in PPT values compared to female patients. ME/CFS was considered present if participants met both the 1994 International Chronic Fatigue Syndrome Study Group criteria for CFS(29) and the 2011 international consensus definition of ME(30), taking the exclusion criteria into account. During the first visit ME/CFS patients were classified as having FM or not. FM was considered present when the diagnosis had been confirmed in the past by a rheumatologist or when patients fulfilled the criteria of FM based on the American College of Rheumatology (ACR) fibromyalgia questionnaire(31). For comparison 22 healthy female subjects underwent the same test.

The study was carried out in accordance with the Declaration of Helsinki. The use of clinical data for descriptive studies (PT1450) and the use of HC (P1411) was approved by the ethics committee of the Slotervaart Hospital, the Netherlands. All patients gave informed consent.

\section{Head-up tilt table test:}

The HUT was performed as described previously(32). Briefly, testing was conducted at least 3 hours after a light meal. Participants were encouraged to ingest an ample amount of fluid on the day of the procedure, but did not drink fluids in the 2 hours before the test. Participants were studied in a climate-controlled room where the temperatures ranged from 22-240 C. Individuals were studied in the supine position for 15 minutes, and for 30 minutes in the upright position (70-degrees). The test was ended after 30 minutes, at the request of the patient, or if the individual developed syncope or pre-syncope. 
Heart rate (HR), systolic and diastolic blood pressures (SBP and DBP) were continuously recorded by finger plethysmography using the Nexfin device (BMeye, Amsterdam, NL) $(33,34)$. An independent radiocontrolled clock was used to mark the starting time of HR and BP recordings as well as the time of the start of tilting. HR and BP data were extracted from the Nexfin device and imported into an Excel spreadsheet. Supine HR and BP data were calculated from the last minute before tilting. Upright HR and BP data were calculated from the last minute of the upright position, and referred to as the end of study (EOS) values. Nasal prongs were placed to measure expired carbon dioxide $\left(\mathrm{CO}_{2}\right)$ concentrations. For the tilt testing component, individuals being treated with medication that could alter HR or BP (beta-adrenergic antagonists, midodrine, fludrocortisone, desmopressin, pyridostigmine bromide, anti-hypertensive medications, or ivabradine) were excluded from this analysis. Individuals being treated with selective serotonin reuptake inhibitors or serotonin norepinephrine reuptake inhibitors continued to take these medications. Patients using neuropathic pain medication (opioids, anti-depressants, anti-epileptics, low dose naltrexone) were also allowed to continue the medication.

Pressure pain thresholds (PPT) and temporal summation (windup):

PPT and windup measurements were performed by one experienced clinician (FCV).Prior to the start of PPT and windup measurements, patients rated their pain at that moment using a paper with a numeric rating scale (NRS) with the numbers placed vertically and on which anchors were given at 0 : no pain, at 1 : very mild pain, at 4: moderate pain, at 8: very strong pain, and at 10: the worst imaginable pain possible. PPT was measured with an analogue Fisher algometer (FDK 40, Wagner Instruments, Greenwich). For this purpose a rubber tip of $1 \mathrm{~cm}^{2}$ was placed on the dorsal surface of the right hand middle finger midway between the first and the second digital joint, and at the middle of the trapezius muscle of the non-dominant shoulder. The rubber tip was placed perpendicular to the skin surface. The right middle finger was chosen irrespective of the left or right dominance, because the left hand middle finger was used for the Nexfin BP measurements. The force was gradually increased at a rate of $1 \mathrm{~kg} / \mathrm{s}$ until the subject indicated that the pain level had been reached. At the two sites the procedure was performed three times with 10 sec intervals. The PPT was calculated as the mean from the last two PPT measurements.

Windup was elicited by 10 applications of the algometer at previously determined PPT value on the same locations as used for PPT measurements(35). Windup measurements started at least 3 minutes after PPT measurements. For each stimulus, pressure was increased at a rate of $1 \mathrm{~kg} / \mathrm{s}$ to the previously determined PPT, where it was maintained for 1 second before being released. Stimuli were presented with an interval of 2 seconds. The same NRS paper was used as described above. Subjects were instructed to rate the pain level ranging from 0 to 10 immediately after each stimulus.

\section{Statistical analysis}

Data were analyzed using the statistical package of Graphpad Prism version 6.05 (Graphpad software, La Jolla, California, USA). All continuous data were tested for normal distribution using the D'AgostinoPearson omnibus normality test, and presented as mean (SD) or as median with the IQR, where appropriate. Nominal data were compared using the Chi-square test. Groups were compared using the ANOVA test for unpaired data. A post-hoc analysis was done where ANOVA showed significant differences, using the t-test. For normally distributed data, comparing pre-HUT and post-HUT values, we used paired t test. In data that were not normally distributed the Mann-Whitney test was used. Due to the multiple comparisons, we chose a conservative $\mathrm{p}$-value of $<0.01$ to be statistically significant.

\section{Results}

A total of 313 individuals with diagnosed ME/CFS underwent HUT during the study period. PPT testing was not performed due to increased severity of hand pain (often in those with hypermobile joints) $(\mathrm{n}=50)$; 15 patients refused PT testing. None of the patients used HR or BP altering drugs before the measurements. This left 248 females to be analyzed. One-hundred-sixty-four patients (66\%) fulfilled the criteria for FM, eighty-four (34\%) did not. As part of the ME/CFS criteria, patients were asked for the presence of muscle complaints. In the group of ME/CFS patients without FM 59/84 (70\%) reported muscle pains. In ME/CFS 
patients with FM, all patients 164/164 (100\%) reported muscle pains.

Table 1 shows the demographic characteristics of the study population. The NRS pain score was significantly different between the three groups ( $\mathrm{p}$ all $<0.0001)$. ME/CFS patients with and without FM showed higher supine heart rates compared to $\mathrm{HC}(\mathrm{p}<0.0005$ and $\mathrm{p}<0.002$, respectively) and higher EOS heart rates compared to HC (both $\mathrm{p}<0.0001$ ). No other variables were significantly different.

Table 2 shows PPT pre- and post-HUT for the finger and the shoulder. PPT of $\mathrm{HC}$ were all significantly higher than of ME/CFS patients (p ranging between $<0.005$ and $<0.0001$ ), except for PPT of the finger in ME/CFS patients without FM ( $\mathrm{p}=0.41)$. Ninety-six ME/CFS patients (38\%) used neuropathic pain medication, 14/84 (17\%) in patients without FM and 82/164 (50\%) in patients with FM. A subgroup analysis showed no differences in PPT between ME/CFS patients with FM using neuropathic pain medication compared to those without. Similarly, no differences in PPT were found between ME/CFS patients without FM using neuropathic pain medication or not (data not shown). Figure 1 shows PPT pre- and post-HUT for the finger and the shoulder in HC (panel A), in ME/CFS patients without FM (panel B), and in ME/CFS patients with FM (panel C). PPT of the finger were significantly higher than PPT of the shoulder in all 3 groups (all $\mathrm{p}<0.0001)$. PPT of HC did not differ pre- and post-HUT for both the finger and the shoulder $(\mathrm{p}=0.14$ and $\mathrm{p}=0.54$, respectively). In both ME/CFS patient groups there was a significant difference pre- and post-HUT for both the finger and the shoulder (p ranging between 0.0001 and $<0.0001$ ). PPT of ME/CFS patients with FM were significantly lower than PPT of ME/CFS patients without FM (all p<0.0001).

Figure 2 shows the graphical representation of the regression line in the 3 groups for the finger (panel A) and the shoulder (panel B). For all time points and groups, the linear regression of windup from stimulus one to ten on both finger and shoulder were highly significant ( $\mathrm{p}$ ranging from 0.0003 to $<0.0001$ ). The slopes of the regression lines pre- and post-HUT for both ME/CFS patient groups were significantly higher than the slopes of the pre- and post-HUT regressions lines of HC (all $\mathrm{p}<0.0001)$. There was no difference in the regression line slopes between pre- and post-HUT within the 3 groups for both the finger and the shoulder. For comparison with the published literature, stimulus 1 pain values were subtracted from stimulus 10 pain values to create a delta windup value. As shown in Figure 3, for both the finger and the shoulder, delta windup values did not differ between pre- and post-HUT in HC and the $2 \mathrm{ME} / \mathrm{CFS}$ patient groups. For both locations a statistically significant difference was found between $\mathrm{HC}$ and the $2 \mathrm{ME} / \mathrm{CFS}$ patient groups (both $\mathrm{p}<0.0001$ ).

\section{Discussion}

In ME/CFS patients sub grouped by the presence or absence of fibromyalgia (FM), we studied pressure pain thresholds (PPT) and the effects of orthostatic stress testing on PPT. First, in the supine position, PPT of the shoulder of ME/CFS patients with and without FM were all significantly lower than of the pre-HUT PPT of HC. The pre-HUT PPT of the finger of ME/CFS patients without FM were not different from that of HC, while that of patients with FM were lower that of HC. Second, post-HUT PPT declined significantly in ME/CFS patients with and without FM, whereas it did not change in HC. Third, the temporal summation (windup), defined by the slopes of the pain severity versus the number of stimuli and also defined by the difference in pain sensation between the first and tenth stimulus, were all higher in ME/CFS patients than in $\mathrm{HC}$ (all $\mathrm{p}<0.0001$ ). Comparing pre- and post-HUT slopes, there were no significant differences in both the two patient groups and in HC, nor was there a difference in pre- and post-HUT windup defined by the delta pain sensation of the first and tenth stimulus.

Baseline PPT: the PPT pre-HUT findings in our study of $164 \mathrm{ME} / \mathrm{CFS}$ patients with FM confirm and extend previous reports showing that FM patients have lower PPT values than $\mathrm{HC}(18,36-38)$. In two ME/CFS studies a lower baseline PPT was found compared to $\mathrm{HC}(26,39)$. ME/CFS patients with FM had a lower PPT than ME/CFS patients without FM(40).

In our study the ME/CFS patients without FM had a similar baseline PPT on the finger compared to HC, and a lower baseline PPT on the shoulder compared to HC. A recent study in HC by Park et al. showed higher $\mathrm{PPT}$ on hands and fingers compared to the PPT of muscular parts, indicating the finger to be relatively less 
sensitive to pain(41). Despite the absence of a difference in PPT of the finger in patients without FM, PPT of the shoulder were significantly lower than that of HC. This could be explained by a high prevalence of muscle pain in even in patients without FM: in our study $70 \%$ of the ME/CFS patients without FM reported muscle pain and $17 \%$ of patients without FM used neuropathic pain medication. Also, NRS pain scores of patients without FM were higher than the NRS pain scores of HC. Taken together, our data on PPT and NRS pain scores and the data of Geisser et al.(40) indicate that pain is a very common phenomenon in adults with ME/CFS, with the pain spectrum ranging from no pain to severe pain/fibromyalgia. Therefore, not only the presence or absence of FM should be taken into account in pain management, but also the PPT values of the patients, irrespective of the diagnose of FM. This approach of using PPT measurements warrants further study.

PPT post-stressor: Earlier studies of the response of PPT to a physiologic stressor among HC have primarily used exercise as the intervention. Studies in HC invariably show that PPT is higher after exercise, indicating hypoalgesia (see for a review Koltyn)(42). In FM patients the data on PPT post-exercise are conflicting: in 2 studies an unchanged PPT in the non-exercised muscle groups were found after isometric contraction exercise $(36,43)$. In contrast, in two other studies an increased PT in the non-exercised muscle group was found in FM patients $(37,38)$. In ME/CFS patients a different pattern was seen: post-exercise PPT increased in $\mathrm{HC}$ in contrast to a decrease in ME/CFS patients $(11,26)$. In the present study, PPT in HC after the orthostatic stressor were unchanged, whereas in both ME/CFS patient groups PPT were significantly lower compared to values pre-HUT (both $\mathrm{p}<0.0001$ ).

In a recent study we showed that during HUT, adults with ME/CFS reported increased fatigue, decreased concentration, increased dizziness/light-headedness, and the provocation or worsening of pain(NCP2019). Moreover, those with ME/CFS experienced a significant decrease of cerebral blood flow compared to HC, and that there was an inverse linear relation between the number of symptoms reported during HUT and the reduction in cerebral blood flow. In other studies, it was shown that working memory function, as assessed by the n-back test, decreased during $\operatorname{HUT}(44,45)$. We therefore hypothesize, that the pain perception increase, as demonstrated by a PPT decrease, may be related to reduction in cerebral blood flow. The pathophysiology of the increased pain sensation after orthostatic stress (possibly related to increased catecholamines, metabolic changes, or inflammatory changes) needs to be addressed in future studies. On the other hand prolonged standing as a physiologic stressor in ME/CFS patients, might also be responsible for the increase in PPT. Future interventions during HUT, like application of a lower body compression could address the question whether the PPT decrease is due to cerebral blood flow reduction or due to prolonged standing(46).

Baseline windup: a recent meta-analysis comparing FM patients with HC showed that windup was significantly higher in FM patients compared to $\mathrm{HC}$ (test for overall effect: $\mathrm{p}=0.0005)(28)$. This meta-analysis analyzed 14 studies, including 298 healthy controls and 318 FM patients. In an ME/CFS study windup in ME/CFS patients $(n=48)$ with a high pain rating score, a non-significant difference compared to $\mathrm{HC}(\mathrm{n}=39)$ was found(47). Our results show, both in ME/CFS patients with and without FM, a highly significantly increased windup in ME/CFS patients (both $\mathrm{p}<0.0001$ ) compared to HC. The differences between our study and of Collin et al.(47) are unexplained but may be due to different inclusion criteria.

Windup post-stressor: in a study using thermal stimulation, a differential effect of exercise was shown in HC $(\mathrm{n}=10)$ vs FM patients $(\mathrm{n}=10)(48)$. Following a maximal exercise stress test in FM patients, windup was higher than pre-exercise data, whereas in $\mathrm{HC}$ windup was lower post-exercise. In the study of Malfliet et al. post submaximal exercise windup between $20 \mathrm{HC}$ and $20 \mathrm{ME} / \mathrm{CFS}$ patients no significant differences were observed(49). In the present study pre-HUT windup of HC was significantly lower than windup of ME/CFS patients with and without FM. Post-HUT data did not change in HC and in the two patient groups. A review of Staud et al. without pointing out any number of patients involved, indicated that part of the windup is related to abnormal pain processing in the spinal cord(2). Possibly, differences in flow reduction of the spinal cord vs central cortical and subcortical areas or different sensitivities to flow reduction may explain the observed differences in PPT and windup, but needs to be studied further.

Limitations. 
The reliability of PPT measurements is dependent upon not only the application technique of the observer, but also on the ability of the participant to provide a consistent verbal indication of the PPT level. It has been previously shown in ME/CFS patients that working memory, as assessed by n-back testing, is reduced during-HUT compared to pre-HUT $(44,45)$. This may have altered the post-HUT assessment of PPT and windup. For reasons of impaired memory and concentration we applied $1 \mathrm{~kg} / \mathrm{s}$ instead of $2 \mathrm{~kg} / \mathrm{s}$ in determining windup, as patient responses might be delayed(35). For the same reason we asked patients to rate windup after every stimulus. Whether this may change the outcomes, needs to be studied in future. The reduction of cerebral blood flow during HUT(50) is variable between ME/CFS patients. To which extent the cerebral blood flow reduction is related to PPT changes is subject of another study. We only studied ME/CFS patients undergoing HUT because of the suspicion of OI. It is unknown whether ME/CFS patients without OI show the same PPT and windup alterations. Also, the effect in male ME/CFS patients is unknown. This single center study is the first on the effects of HUT on PPT and windup and needs to be replicated by others.

\section{Conclusions.}

This is first study showing the influence of orthostatic stress on pain perception in ME/CFS patients. After orthostatic stress PPT is decreased in ME/CFS patients, with or without fibromyalgia, whereas in healthy controls PPT did not change. In contrast, after orthostatic stress windup is unchanged in both $\mathrm{HC}$ and the two patient groups, but significantly increased in the two patient groups compared to HC.

\section{Figure Legends}

Figure 1. Pressure Pain thresholds of the finger and shoulder pre- and post-HUT. Panel A shows healthy controls, panel B ME/CFS patients without fibromyalgia and panel C ME/CFS patients with fibromyalgia. HUT: head-up tilt test; PPT: pressure pain thresholds.

Figure 2. Temporal summation on the finger and shoulder pre- and post-HUT for HC, ME/CFS patients without and with fibromyalgia. For clarity of the figure mean +/- SEM are shown. Panel A shows the windup for the finger and Panel B for the shoulder. The slopes within the groups (pre- and post-HUT) were not statistically significant.

FM: fibromyalgia, +: with; -: without; HC: healthy controls; pre: before head-up tilt test; post: after head-up tilt test

Figure 3. Delta windup (stimulus 10 minus stimulus 1) pre- and post-HUT in healthy controls, in ME/CFS patients without fibromyalgia and in ME/CFS patients with fibromyalgia. Panel A shows the windup for the finger and Panel B for the shoulder.

FM: fibromyalgia; HUT: head-up tilt test

Table 1. Demographic data and hemodynamic HUT results of the study population*

\begin{tabular}{|c|c|c|c|c|c|c|c|}
\hline & Group $1 \mathrm{HC}$ & $\begin{array}{l}\text { Group } 2 \\
\text { ME/CFS } \\
\text { without FM }\end{array}$ & $\begin{array}{l}\text { Group } 3 \\
\text { ME/CFS } \\
\text { with FM }\end{array}$ & $\begin{array}{l}\text { ANOVA } 1 \\
\text { vs } 2 \text { vs } 3\end{array}$ & Group 2 vs 3 & Group 1 vs 2 & Group 1 vs 3 \\
\hline $\begin{array}{l}\text { Age } \\
\text { (years) }\end{array}$ & $41(14)$ & $40(12)$ & $38(11)$ & 0.28 & & & \\
\hline $\begin{array}{l}\text { Disease } \\
\text { duration } \\
\text { (years)* }\end{array}$ & & $10(4-17)$ & $9(6-15)$ & & 0.84 & & \\
\hline $\begin{array}{l}\text { Height } \\
(\mathrm{cm})\end{array}$ & $171(5)$ & $171(7)$ & $170(6)$ & 0.43 & & & \\
\hline $\begin{array}{l}\text { Weight } \\
(\mathrm{kg})\end{array}$ & $72(16)$ & $71(14)$ & $72(16)$ & 0.74 & & & \\
\hline $\begin{array}{l}\mathrm{BMI} \\
\left(\mathrm{kg} / \mathrm{m}^{2}\right)\end{array}$ & $24.8(5.1)$ & $24.2(5.0)$ & $25.0(5.6)$ & 0.51 & & & \\
\hline
\end{tabular}




\begin{tabular}{|c|c|c|c|c|c|c|c|}
\hline & Group $1 \mathrm{HC}$ & $\begin{array}{l}\text { Group } 2 \\
\text { ME/CFS } \\
\text { without FM }\end{array}$ & $\begin{array}{l}\text { Group } 3 \\
\text { ME/CFS } \\
\text { with FM }\end{array}$ & $\begin{array}{l}\text { ANOVA } 1 \\
\text { vs } 2 \text { vs } 3\end{array}$ & Group 2 vs 3 & Group 1 vs 2 & Group 1 vs 3 \\
\hline $\begin{array}{l}\text { NRS } \\
\text { pain* }\end{array}$ & $0(0-1.3)$ & $3(1-5)$ & $5(3-6)$ & $<0.0001$ & $<0.0001$ & $<0.0001$ & $<0.0001$ \\
\hline $\begin{array}{l}\text { Heart rate } \\
\text { supine } \\
(\mathrm{bpm})\end{array}$ & $66(13)$ & $79(8)$ & $77(12)$ & $<0.001$ & 0.31 & $<0.002$ & $<0.0005$ \\
\hline $\begin{array}{l}\text { Heart rate } \\
\text { EOS } \\
(\mathrm{bpm})\end{array}$ & $80(14)$ & $98(18)$ & $103(20)$ & $<0.0001$ & 0.08 & $<0.0001$ & $<0.0001$ \\
\hline $\begin{array}{l}\text { SBP } \\
\text { supine } \\
(\mathrm{mmHg})\end{array}$ & $137(16)$ & $137(16)$ & $136(15)$ & 0.84 & & & \\
\hline $\begin{array}{l}\text { SBP EOS } \\
(\mathrm{mmHg})\end{array}$ & $125(16)$ & $123(19)$ & $125(18)$ & 0.81 & & & \\
\hline $\begin{array}{l}\text { DBP } \\
\text { supine } \\
(\mathrm{mmHg})\end{array}$ & $79(7)$ & $79(8)$ & $79(7)$ & 0.87 & & & \\
\hline $\begin{array}{l}\text { DBP EOS } \\
(\mathrm{mmHg})\end{array}$ & $81(9)$ & $82(12)$ & $83(10)$ & 0.57 & & & \\
\hline
\end{tabular}

DBP: diastolic blood pressure; EOS: end of study; FM: fibromyalgia; HC: healthy controls; SBP: systolic blood pressure; NRS: numeric rating scale. *data with median and IQR.

Table 2. Pressure pain threshold (PPT) data pre- and post-HUT of the study population

\begin{tabular}{|c|c|c|c|c|c|c|c|}
\hline & Group $1 \mathrm{HC}$ & $\begin{array}{l}\text { Group } 2 \\
\text { ME/CFS } \\
\text { without FM }\end{array}$ & $\begin{array}{l}\text { Group } 3 \\
\text { ME/CFS } \\
\text { with FM }\end{array}$ & $\begin{array}{l}\text { ANOVA } 1 \\
\text { vs } 2 \text { vs } 3\end{array}$ & Group 2 vs 3 & Group 1 vs 2 & Group 1 vs 3 \\
\hline $\begin{array}{l}\text { PPT } \\
\text { finger } \\
\text { pre-HUT }\end{array}$ & $4.7(1.6)$ & $5.0(1.6)$ & $2.0(0.9)$ & $<0.0001$ & $<0.0001$ & 0.41 & $<0.0001$ \\
\hline $\begin{array}{l}\text { PPT } \\
\text { finger } \\
\text { post-HUT }\end{array}$ & $4.4(1.5)$ & $3.3(1.5)$ & $1.5(0.8)$ & $<0.0001$ & $<0.0001$ & $<0.0001$ & $<0.0001$ \\
\hline $\begin{array}{l}\text { PPT } \\
\text { shoulder } \\
\text { pre-HUT }\end{array}$ & $2.8(1.0)$ & $2.2(0.9)$ & $1.2(0.5)$ & $<0.0001$ & $<0.0001$ & $<0.005$ & $<0.0001$ \\
\hline $\begin{array}{l}\text { PPT } \\
\text { shoulder } \\
\text { post-HUT }\end{array}$ & $2.9(1.0)$ & $1.9(1.0)$ & $1.0(0.5)$ & $<0.0001$ & $<0.0001$ & $<0.0001$ & $<0.0001$ \\
\hline
\end{tabular}

FM: fibromyalgia; HC: healthy controls; HUT: head-up tilt test; PPT: pressure pain threshold.

Figure 1 A-C Pressure Pain thresholds of the finger and shoulder pre- and post-HUT.

Figure 2 A-B Temporal summation on the finger and shoulder pre- and post-HUT for HC, ME/CFS patients without and with fibromyalgia. 
Figure 3 A-B Delta windup (stimulus 10 minus stimulus 1) pre- and post-HUT in healthy controls, in ME/CFS patients without fibromyalgia and in ME/CFS patients with fibromyalgia

\section{References}

1. Bradley LA, McKendree-Smith NL, Alarcon GS. Pain complaints in patients with fibromyalgia versus chronic fatigue syndrome. Current review of pain. 2000;4(2):148-57.

2. Staud R, Smitherman ML. Peripheral and central sensitization in fibromyalgia: pathogenetic role. Curr Pain Headache Rep. 2002;6(4):259-66.

3. Banic B, Petersen-Felix S, Andersen OK, Radanov BP, Villiger PM, Arendt-Nielsen L, et al. Evidence for spinal cord hypersensitivity in chronic pain after whiplash injury and in fibromyalgia. Pain. 2004;107(12):7-15.

4. Jason LA, Richman JA, Rademaker AW, Jordan KM, Plioplys AV, Taylor RR, et al. A community-based study of chronic fatigue syndrome. Archives of internal medicine. 1999;159(18):2129-37.

5. Nijs J, Meeus M, Van Oosterwijck J, Roussel N, De Kooning M, Ickmans K, et al. Treatment of central sensitization in patients with 'unexplained' chronic pain: what options do we have? Expert opinion on pharmacotherapy. 2011;12(7):1087-98.

6. Meeus M, Nijs J. Central sensitization: a biopsychosocial explanation for chronic widespread pain in patients with fibromyalgia and chronic fatigue syndrome. Clinical rheumatology. 2007;26(4):465-73.

7. Meeus M, Nijs J, Huybrechts S, Truijen S. Evidence for generalized hyperalgesia in chronic fatigue syndrome: a case control study. Clinical rheumatology. 2010.

8. Duprez DA, De Buyzere ML, Drieghe B, Vanhaverbeke F, Taes Y, Michielsen W, et al. Long- and shortterm blood pressure and RR-interval variability and psychosomatic distress in chronic fatigue syndrome. Clin Sci (Lond). 1998;94(1):57-63.

9. Meeus M, Roussel NA, Truijen S, Nijs J. Reduced pressure pain thresholds in response to exercise in chronic fatigue syndrome but not in chronic low back pain: an experimental study. J Rehabil Med. 2010;42(9):884-90.

10. Van Oosterwijck J, Nijs J, Meeus M, Lefever I, Huybrechts L, Lambrecht L, et al. Pain inhibition and postexertional malaise in myalgic encephalomyelitis/chronic fatigue syndrome: an experimental study. J Intern Med. 2010;268(3):265-78.

11. Whiteside A, Hansen S, Chaudhuri A. Exercise lowers pain threshold in chronic fatigue syndrome. Pain. 2004;109(3):497-9.

12. Hardy JD, Wolff HG, Goodell H. Studies on Pain. A New Method for Measuring Pain Threshold: Observations on Spatial Summation of Pain. J Clin Invest. 1940;19(4):649-57.

13. Chesterton LS, Sim J, Wright CC, Foster NE. Interrater reliability of algometry in measuring pressure pain thresholds in healthy humans, using multiple raters. Clin J Pain. 2007;23(9):760-6.

14. Nussbaum EL, Downes L. Reliability of clinical pressure-pain algometric measurements obtained on consecutive days. Phys Ther. 1998;78(2):160-9.

15. Delaney GA, McKee AC. Inter- and intra-rater reliability of the pressure threshold meter in measurement of myofascial trigger point sensitivity. Am J Phys Med Rehabil. 1993;72(3):136-9.

16. Persson AL, Brogardh C, Sjolund BH. Tender or not tender: test-retest repeatability of pressure pain thresholds in the trapezius and deltoid muscles of healthy women. J Rehabil Med. 2004;36(1):17-27.

17. Tunks E, McCain GA, Hart LE, Teasell RW, Goldsmith CH, Rollman GB, et al. The reliability of examination for tenderness in patients with myofascial pain, chronic fibromyalgia and controls. J Rheumatol. 
1995;22(5):944-52.

18. Goubert D, Danneels L, Graven-Nielsen T, Descheemaeker F, Meeus M. Differences in Pain Processing Between Patients with Chronic Low Back Pain, Recurrent Low Back Pain, and Fibromyalgia. Pain Physician. 2017;20(4):307-18.

19. King CD, Jastrowski Mano KE, Barnett KA, Pfeiffer M, Ting TV, Kashikar-Zuck S. Pressure Pain Threshold and Anxiety in Adolescent Females With and Without Juvenile Fibromyalgia: A Pilot Study. Clin J Pain. 2017;33(7):620-6.

20. Cheatham SW, Kolber MJ, Mokha GM, Hanney WJ. Concurrent validation of a pressure pain threshold scale for individuals with myofascial pain syndrome and fibromyalgia. J Man Manip Ther. 2018;26(1):25-35.

21. Harden RN, Revivo G, Song S, Nampiaparampil D, Golden G, Kirincic M, et al. A critical analysis of the tender points in fibromyalgia. Pain Med. 2007;8(2):147-56.

22. Aparicio VA, Carbonell-Baeza A, Ortega FB, Estevez F, Ruiz JR, Delgado-Fernandez M. Usefulness of tenderness to characterise fibromyalgia severity in women. Clin Exp Rheumatol. 2011;29(6 Suppl 69):S28-33.

23. Gomez-Perretta C, Trinanes Y, Gonzalez-Villar AJ, Carrillo-de-la-Pena MT. Evaluation of the accuracy of several symptoms and domains in distinguishing patients diagnosed with fibromyalgia from healthy controls. Clin Exp Rheumatol. 2016;34(2 Suppl 96):S14-25.

24. Davenport TE, Stevens SR, Baroni K, Van NM, Snell CR. Diagnostic accuracy of symptoms characterising chronic fatigue syndrome. DisabilRehabil. 2011;33(19-20):1768-75.

25. Vanness JM, Stevens SR, Bateman L, Stiles TL, Snell CR. Postexertional malaise in women with chronic fatigue syndrome. JWomens Health (Larchmt). 2010;19(2):239-44.

26. Meeus M, Roussel NA, Truijen S, Nijs J. Reduced pressure pain thresholds in response to exercise in chronic fatigue syndrome but not in chronic low back pain: an experimental study. JRehabilMed. 2010;42(9):884-90.

27. Staud R, Mokthech M, Price DD, Robinson ME. Evidence for sensitized fatigue pathways in patients with chronic fatigue syndrome. Pain. 2015;156(4):750-9.

28. O'Brien AT, Deitos A, Trinanes Pego Y, Fregni F, Carrillo-de-la-Pena MT. Defective Endogenous Pain Modulation in Fibromyalgia: A Meta-Analysis of Temporal Summation and Conditioned Pain Modulation Paradigms. J Pain. 2018;19(8):819-36.

29. Fukuda K, Straus SE, Hickie I, Sharpe MC, Dobbins JG, Komaroff A. The chronic fatigue syndrome: a comprehensive approach to its definition and study. International Chronic Fatigue Syndrome Study Group. AnnInternMed. 1994;121(12):953-9.

30. Carruthers BM, van de Sande MI, DE Meirleir KL, Klimas NG, Broderick G, Mitchell T, et al. Myalgic encephalomyelitis: International Consensus Criteria. JInternMed. 2011;270(4):327-38.

31. Wolfe F, Clauw DJ, Fitzcharles MA, Goldenberg DL, Hauser W, Katz RL, et al. 2016 Revisions to the 2010/2011 fibromyalgia diagnostic criteria. Semin Arthritis Rheum. 2016;46(3):319-29.

32. van Campen C, Verheugt FWA, Visser FC. Cerebral blood flow changes during tilt table testing in healthy volunteers, as assessed by Doppler imaging of the carotid and vertebral arteries. Clin Neurophysiol Pract. 2018;3:91-5.

33. Eeftinck Schattenkerk DW, van Lieshout JJ, van den Meiracker AH, Wesseling KR, Blanc S, Wieling $\mathrm{W}$, et al. Nexfin noninvasive continuous blood pressure validated against Riva-Rocci/Korotkoff. Am J Hypertens. 2009;22(4):378-83.

34. Martina JR, Westerhof BE, van Goudoever J, de Beaumont EM, Truijen J, Kim YS, et al. Noninvasive continuous arterial blood pressure monitoring with Nexfin(R). Anesthesiology. 2012;116(5):1092-103. 
35. Cathcart S, Winefield AH, Rolan P, Lushington K. Reliability of temporal summation and diffuse noxious inhibitory control. Pain Res Manag. 2009;14(6):433-8.

36. Lannersten L, Kosek E. Dysfunction of endogenous pain inhibition during exercise with painful muscles in patients with shoulder myalgia and fibromyalgia. Pain. 2010;151(1):77-86.

37. Staud R, Robinson ME, Weyl EE, Price DD. Pain variability in fibromyalgia is related to activity and rest: role of peripheral tissue impulse input. J Pain. 2010;11(12):1376-83.

38. Kadetoff D, Kosek E. The effects of static muscular contraction on blood pressure, heart rate, pain ratings and pressure pain thresholds in healthy individuals and patients with fibromyalgia. European journal of pain. 2007;11(1):39-47.

39. Winger A, Kvarstein G, Wyller VB, Sulheim D, Fagermoen E, Smastuen MC, et al. Pain and pressure pain thresholds in adolescents with chronic fatigue syndrome and healthy controls: a cross-sectional study. BMJ Open. 2014;4(9):e005920.

40. Geisser ME, Gracely RH, Giesecke T, Petzke FW, Williams DA, Clauw DJ. The association between experimental and clinical pain measures among persons with fibromyalgia and chronic fatigue syndrome. EurJPain. 2007;11(2):202-7.

41. Park MY, Han D, Lim JH, Shin MK, Han YR, Kim DH, et al. Assessment of pressure pain thresholds in collisions with collaborative robots. PLoS One. 2019;14(5):e0215890.

42. Koltyn KF. Analgesia following exercise: a review. Sports Med. 2000;29(2):85-98.

43. Staud R, Robinson ME, Price DD. Isometric exercise has opposite effects on central pain mechanisms in fibromyalgia patients compared to normal controls. Pain. 2005;118(1-2):176-84.

44. Stewart JM, Medow MS, Messer ZR, Baugham IL, Terilli C, Ocon AJ. Postural neurocognitive and neuronal activated cerebral blood flow deficits in young chronic fatigue syndrome patients with postural tachycardia syndrome. AmJPhysiol Heart CircPhysiol. 2012;302(5):H1185-H94.

45. Medow MS, Sood S, Messer Z, Dzogbeta S, Terilli C, Stewart JM. Phenylephrine alteration of cerebral blood flow during orthostasis: effect on n-back performance in chronic fatigue syndrome. J Appl Physiol (1985). 2014;117(10):1157-64.

46. Streeten DH, Thomas D, Bell DS. The roles of orthostatic hypotension, orthostatic tachycardia, and subnormal erythrocyte volume in the pathogenesis of the chronic fatigue syndrome. Am J Med Sci. $2000 ; 320(1): 1-8$.

47. Collin SM, Nijs J, Meeus M, Polli A, Willekens B, Ickmans K. Endogenous Pain Facilitation Rather Than Inhibition Differs Between People with Chronic Fatigue Syndrome, Multiple Sclerosis, and Controls: An Observational Study. Pain Physician. 2017;20(4):E489-E97.

48. Vierck CJ, Jr., Staud R, Price DD, Cannon RL, Mauderli AP, Martin AD. The effect of maximal exercise on temporal summation of second pain (windup) in patients with fibromyalgia syndrome. J Pain. 2001;2(6):334-44.

49. Malfliet A, Pas R, Brouns R, De Win J, Hatem SM, Meeus M, et al. Cerebral Blood Flow and Heart Rate Variability in Chronic Fatigue Syndrome: A Randomized Cross-Over Study. Pain Physician. 2018;21(1):E13-E24.

50. van Campen C, Verheugt FWA, Rowe PC, Visser FC. Cerebral blood flow is reduced in ME/CFS during head-up tilt testing even in the absence of hypotension or tachycardia: A quantitative, controlled study using Doppler echography. Clin Neurophysiol Pract. 2020;5:50-8.

\section{Acknowledgements}


Dr. Rowe is supported by the Sunshine Natural Wellbeing Foundation Professorship of Chronic Fatigue and Related Disorders.

\section{Conflict of Interest}

The authors declare that the research was conducted in the absence of any commercial or financial relationships that could be construed as a potential conflict of interest.

\section{Author Contributions}

CMCVC, PCR, and FCV conceived the study, CMCVC and FCV collected the data, CMCVC performed the primary data analysis and FCV and PCR performed secondary data analyses. All authors were involved in the drafting and review of the manuscript.

\section{Funding}

This study was performed without grant funding.

\section{Data Availability Statement}

The raw data supporting the conclusions of this manuscript will be made available by the authors, without undue reservation, to any qualified researcher. 


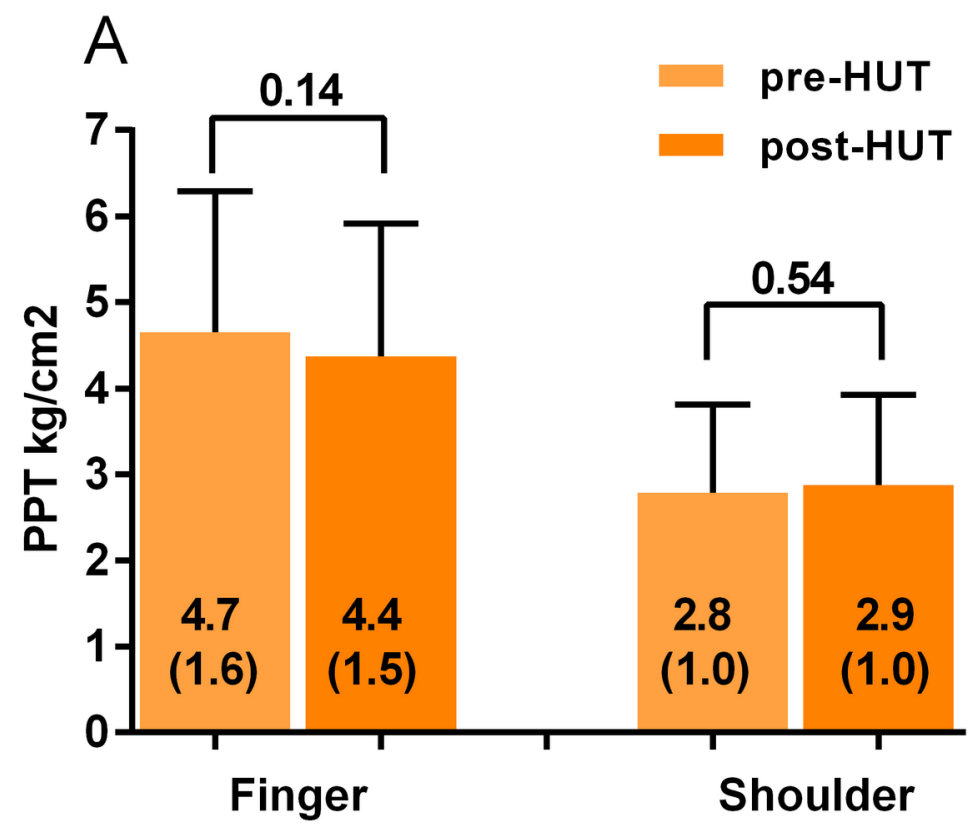

Healthy controls $(n=22)$
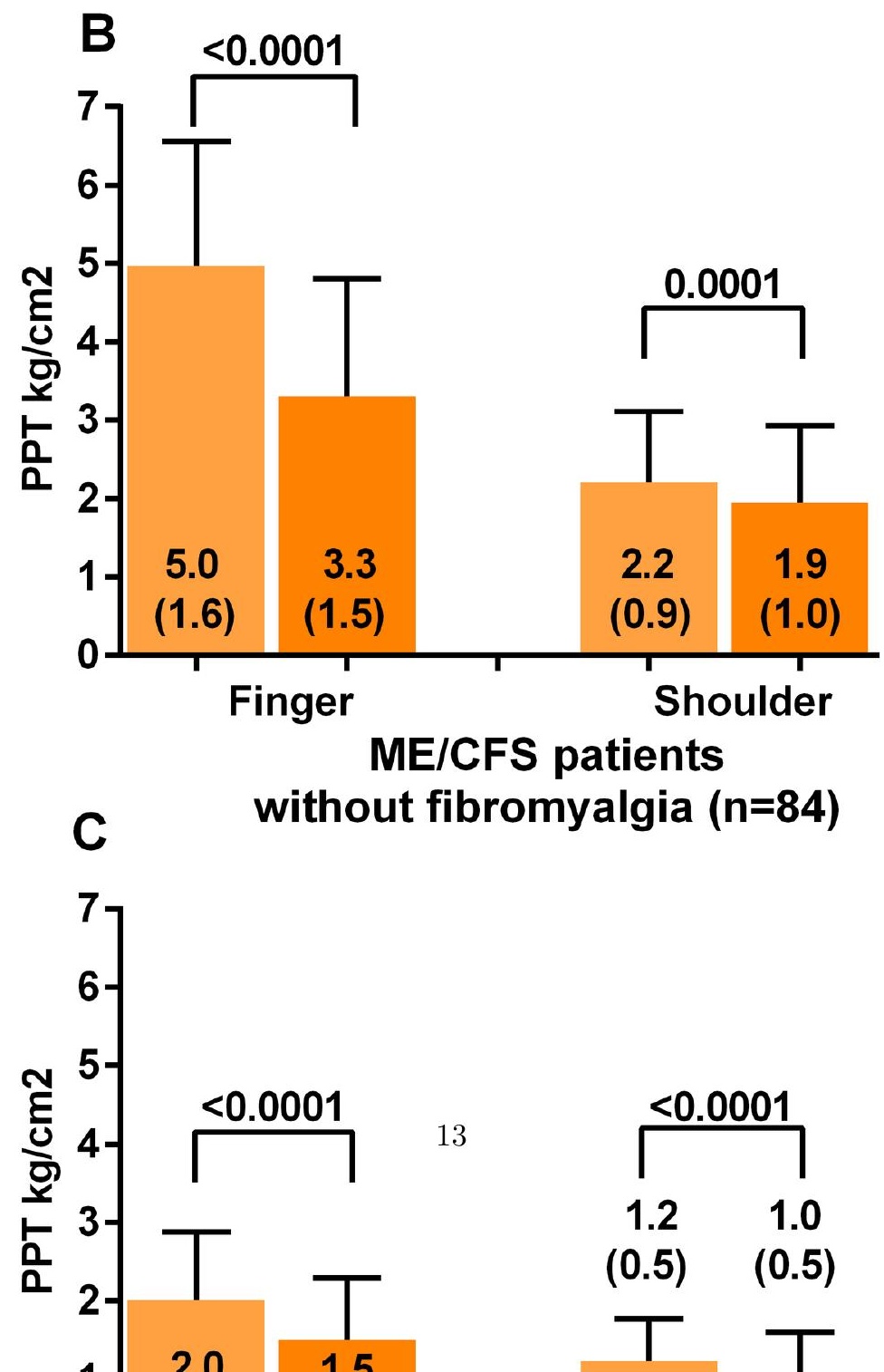

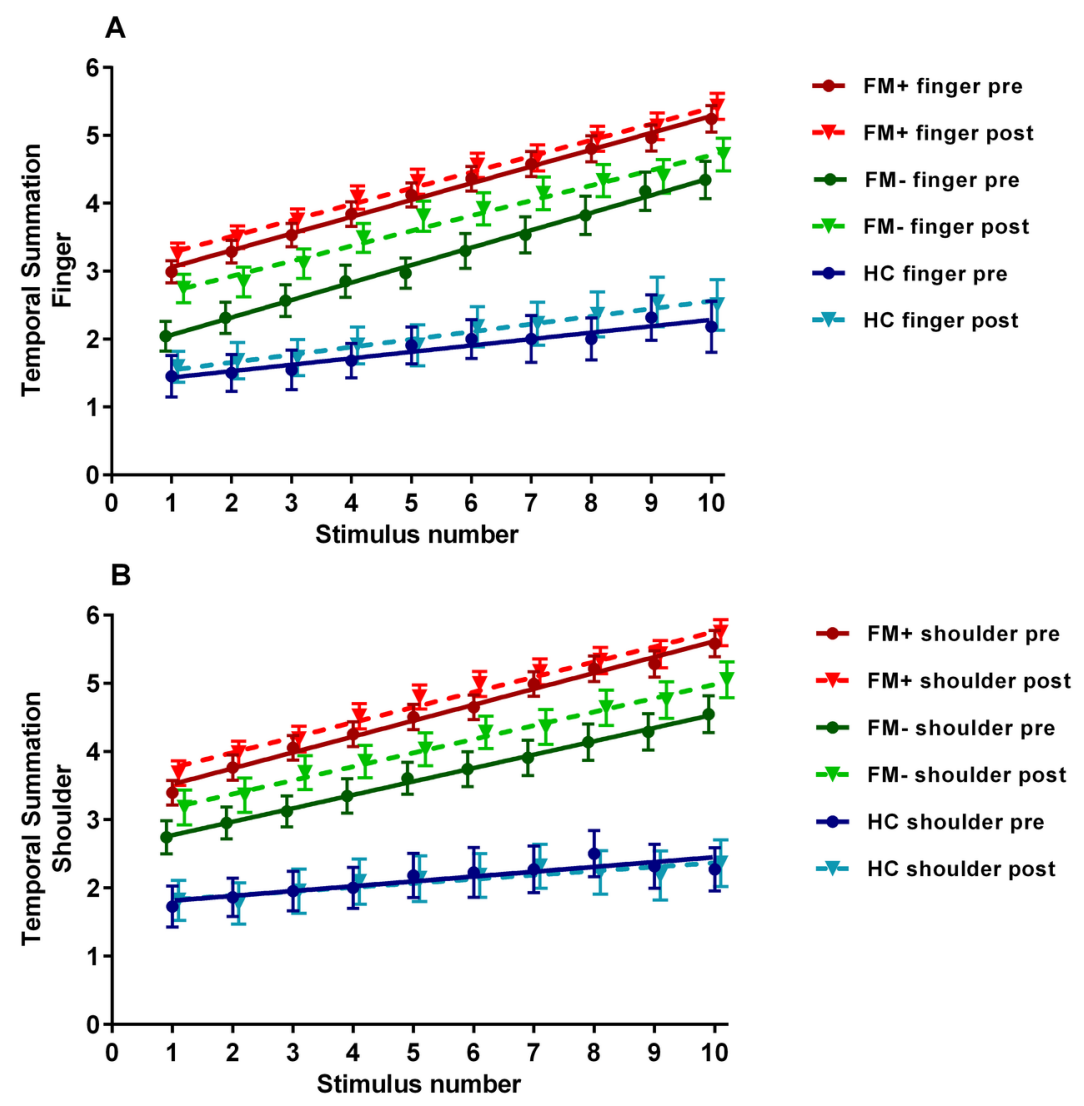

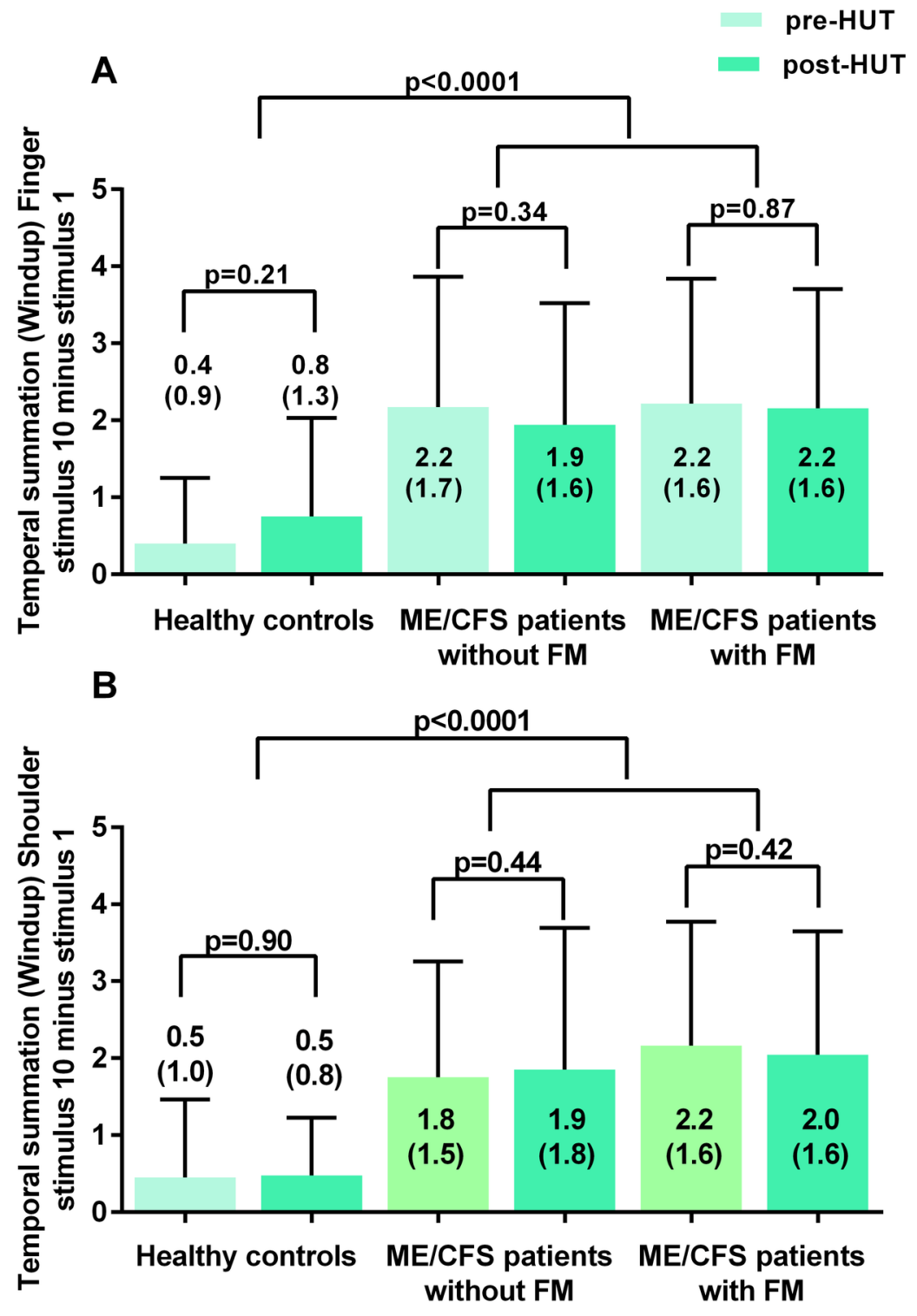